\title{
Knowledge and attitudes of dental interns toward denture adhesives in King Saud University, Riyadh, Saudi Arabia
}

\author{
Sara Mohammad Al Taweel ${ }^{1}$, Huda Ahmed Al Shehri ${ }^{1}$
}

Correspondence: Dr. Sara Mohammad Al Taweel

Email: saltaweel@ksu.edu.sa

\begin{abstract}
'Department of Prosthetic Dental Sciences, College of Dentistry, King Saud University, Riyadh, Kingdom of Saudi Arabia
\end{abstract}

\section{ABSTRACT}

Objective: The objective of this study was to evaluate the knowledge and attitudes of dental interns at King Saud University College of Dentistry (KSUCD) regarding denture adhesives (DAs). Materials and Methods: Surveys were distributed to dental interns at KSUCD $(n=100)$. Cross-tabulations with the Pearson's Chi-square test were used to compare variables using the Statistical Package for Social Sciences $(P \leq 0.05)$. Results: Approximately, $85.5 \%$ of the respondents had learned about DAs as part of their undergraduate curriculum, $71 \%$ agree that DAs can be a beneficial adjunct in the fabrication of dentures, and $87 \%$ agree that dentists should routinely inform all denture patients of the proper use and misuse of DAs. Conclusion: Most of the participants have adequate knowledge and attitude toward DAs.

Key words: Attitude, denture adhesives, knowledge, questionnaire

\section{INTRODUCTION}

Denture adhesives (DAs) are used to adhere a denture to the oral mucosa. They are available in different types including powder, creams, liquid, or wafers. ${ }^{[1]}$ Although the use of DAs is very common in complete denture wearers and DAs are easily available as over-the-counter products, dental professionals and prosthodontic educators have been shown to be reluctant to endorse these products. ${ }^{[2]}$

In general, DAs are indicated for patients with inadequate denture retention and stability, patients with neuromuscular disorders such as Parkinson's disease, or in patients with xerostomia. On the other hand, DAs contraindicated in patients with allergy to DAs materials, severe inadequacies in function

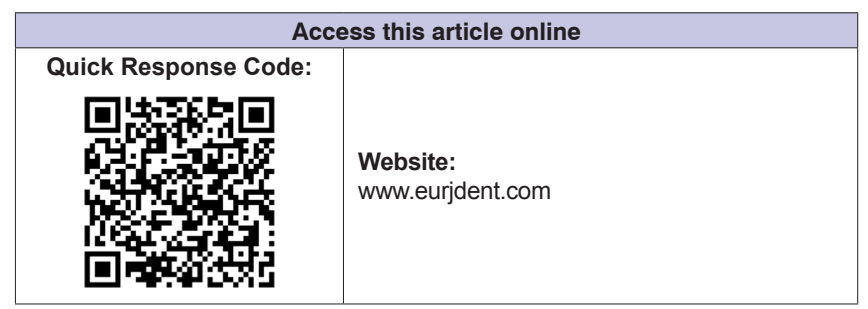

and retention of complete denture, excessive bone resorption, or in patients who are unable to maintain adequate oral hygiene. ${ }^{[3,4]}$

There is a conflict among dental professionals regarding the use of DAs. This conflict can be described as the traditional historical approach versus the advocate approach. ${ }^{[5]}$ While the traditional historical approach considers DAs to be a poor substitute for a proper fit that mask professional shortcomings, ${ }^{[2,6]}$ dentists who support the advocate approach believe that DAs can assist in clinical procedures, alleviate patients' fears with respect to the fit of the final processed denture, increase patient satisfaction, and help during jaw relation establishment and the fitting of trial dentures. ${ }^{[7,8]}$

This is an open access article distributed under the terms of the Creative Commons Attribution-NonCommercial-ShareAlike 3.0 License, which allows others to remix, tweak, and build upon the work non-commercially, as long as the author is credited and the new creations are licensed under the identical terms.

For reprints contact: reprints@medknow.com

How to cite this article: Al Taweel SM, Al Shehri HA. Knowledge and attitudes of dental interns toward denture adhesives in King Saud University, Riyadh, Saudi Arabia. Eur J Dent 2016;10:536-40.

DOI: $10.4103 / 1305-7456.195182$ 
It is important that dentists inform patients of the advantages and disadvantages of DAs, using DAs according to the manufacturer instructions following specific guidelines for application and removal to prevent potential misuse. Furthermore, instruct and demonstrate clinically how to apply and remove adhesives correctly, and educate patients about the significance of routine recall appointments for removable prostheses. ${ }^{[3]}$

Several studies have reported on denture wearers' knowledge regarding $\mathrm{DAs}^{[9,10]}$ as well as patient disposition toward these materials. ${ }^{[2,11,12]}$ Although little data have been obtained about the attitudes of dental professionals regarding DAs ${ }^{[5,13,14]}$ and undergraduate dental students, ${ }^{[15,16]}$ dental interns' knowledge and attitudes regarding DAs remain unclear.

Because DAs have been accepted by patients worldwide and the increasing number of patients who rely on their dentists to provide more reliable information, it means that dental intern students graduating from dental schools should have sound knowledge and comprehensive understanding of the DAs' usage. From the above-mentioned perspectives, we conducted this study to evaluate the knowledge and attitudes of dental interns toward DAs at King Saud University College of Dentistry (KSUCD).

\section{MATERIALS AND METHODS}

One hundred questionnaires were distributed to all male $(n=60)$ and female $(n=40)$ dental interns at KSUCD, Riyadh, Saudi Arabia, between April 15 and 30, 2015. Participation was voluntary and anonymous. The questionnaire was reviewed, and the study was ethically approved by the College of Dentistry Research Center, King Saud University, Riyadh, Saudi Arabia. Dental interns' samples were selected to participate in this study because their daily clinical practice is usually based on what they have been learned during their undergraduate study. Hence, at this stage of training, it was interesting to know their knowledge and attitude regarding DAs.

During undergraduate education, the students study in English; for this reason, the questionnaire was presented in English comprising 13 questions in two sections. The first part comprised six self-structured questions to assess the current knowledge of dental interns toward DAs. There were two response options: "No" and "Yes." The second part comprised seven questions that included twenty statements to rate the attitudes of dental interns toward DAs; the questions were adopted from a previous study. ${ }^{[5]}$ Respondents were required to select one response for each statement based on their level of agreement using a 5-point Likert scale (strongly agree [SA], agree $[\mathrm{A}]$, indifferent $[\mathrm{I}]$, disagree $[\mathrm{D}]$, and strongly disagree [SD]).

The data obtained from the survey were analyzed using the Statistical Package for the Social Sciences database (SPSS 16 for Windows, IBM Corporation, Armonk, NY, USA). Cross-tabulations with the Pearson's Chi-square test were used to compare variables. A statistically significance level of $P \leq 0.05$ was established.

\section{RESULTS}

Out of the 100 questionnaires distributed, 69 were answered. Response rate was $82.5 \%$ for females $(n=33)$ and $60 \%$ for males $(n=36)$, with a total of $69 \%$. Table 1 shows the questionnaire items and the percentages of (yes) answers for male and female dental interns at KSUCD.

No significant differences between male and female interns were found for the first part of the questionnaire $(P>0.05)$. For the question "have you heard about DAs?," $97.1 \%$ of all the respondents have answered "Yes." Nearly, 85.5\% had learned about

\begin{tabular}{|c|c|c|c|c|}
\hline \multicolumn{5}{|c|}{ Part 1} \\
\hline \multirow[t]{2}{*}{$\begin{array}{l}\text { Question } \\
\text { number }\end{array}$} & \multirow[t]{2}{*}{ Questions } & \multicolumn{3}{|c|}{$\begin{array}{c}\text { Results (percentage of } \\
\text { yes response) }\end{array}$} \\
\hline & & Male & Female & $\begin{array}{c}\text { Total } \\
\text { response }\end{array}$ \\
\hline 1 & Have you heard about DA? & 97.2 & 97 & 97.1 \\
\hline 2 & $\begin{array}{l}\text { In your undergraduate } \\
\text { curriculum, have you ever } \\
\text { been taught about DA? }\end{array}$ & 86.1 & 84.8 & 85.5 \\
\hline \multirow[t]{5}{*}{3} & You know about DA from & & & \\
\hline & Books & 41.2 & 37.5 & 39 \\
\hline & Lectures & 94.1 & 93.8 & 93 \\
\hline & Conferences & 14.7 & 0 & 7 \\
\hline & Visual media & 11.8 & 9.4 & 10 \\
\hline 4 & $\begin{array}{l}\text { Have you ever seen } \\
\text { DA in the clinic? }\end{array}$ & 75 & 57.6 & 66.7 \\
\hline 5 & $\begin{array}{l}\text { Have you ever use } \\
\text { DA in the clinic? }\end{array}$ & 58.3 & 45.5 & 52.2 \\
\hline 6 & $\begin{array}{l}\text { Have you ever let your } \\
\text { patient use DA? }\end{array}$ & 52.8 & 45.5 & 49.3 \\
\hline
\end{tabular}


DAs as part of their undergraduate curriculum. Most participants knew about DAs from lectures (93\%), followed by books $(39 \%)$, visual media $(10 \%)$, and conferences $(7 \%)$. Regarding the clinical use of DAs, $66.7 \%$ of the respondents had seen DAs used in clinical practice, $52.2 \%$ had used them on their patients, and $49.3 \%$ had recommended that their patients use DAs at home.

Table 2 shows the questionnaire items and the results of the second part of the questionnaire, regarding the attitudes toward DAs. The results showed no statistically significant differences between male and female respondents $(P>0.05)$ except for question 9 , statement $(C)(P=0.033)$ where $2.8 \%$ of the males and $15.2 \%$ of the females disagree; $11.1 \%$ of the males and $21.2 \%$ of the females were indifferent; and $86 \%$ of the males and $63.7 \%$ of the females agree.
In question seven, most of the respondents agreed in using DAs in some statements such as "to enhance the retention and stability of the prosthesis, provide psychological comfort to the denture and to encourage improper clinical practice." On the other hand, most of the respondents disagreed that "DAs mask the underlying denture problems and prevent patients from showing in recall appointments." In question eight, the respondents disagree that DAs contribute to the development of oral cancer and leukoplakia. While they agree that, it contributes to the development of denture stomatitis, candidiasis, and imbalance in the oral flora. On the other hand, they were indifferent that DAs can contribute to the development of the alveolar ridge resorption. In question nine, all the respondents had an agreement that DAs can be useful to help in stabilize the denture during jaw relation visit, reduce patients' fear, overcome patients'

\begin{tabular}{|c|c|c|c|c|}
\hline \multicolumn{5}{|c|}{ Part 2} \\
\hline \multirow{2}{*}{$\begin{array}{l}\text { Question } \\
\text { number }\end{array}$} & \multirow[t]{2}{*}{ Questions } & \multicolumn{3}{|c|}{ Total responses (male and female) } \\
\hline & & Disagree (\%) & Indifferent (\%) & Agree (\%) \\
\hline \multirow[t]{6}{*}{7} & $\begin{array}{l}\text { DAs have the potential (either positive } \\
\text { or negative) to the following }\end{array}$ & & & \\
\hline & Enhancing the retention and stability of the prosthesis & 5.7 & 7.2 & 87.1 \\
\hline & Encourage improper clinical practice & 36.2 & 23.2 & 40.6 \\
\hline & Providing a psychological comfort to the denture patients & 4.3 & 11.6 & 84.1 \\
\hline & Masking underlying denture problems & 40.6 & 21.7 & 37.7 \\
\hline & $\begin{array}{l}\text { Prevent patients from showing in recall and/or to avoid fees } \\
\text { associated with denture care, adjustment, or replacement }\end{array}$ & 34.7 & 31.9 & 33.4 \\
\hline \multirow[t]{7}{*}{8} & $\begin{array}{l}\text { In your opinion, DAs can contribute to the } \\
\text { development of the following conditions }\end{array}$ & & & \\
\hline & Oral cancer & 55.2 & 42 & 2.8 \\
\hline & Denture stomatitis & 21.7 & 26.1 & 52.2 \\
\hline & Leukoplakia & 47.8 & 43.5 & 8.7 \\
\hline & Candidiasis & 14.5 & 18.8 & 66.7 \\
\hline & An imbalance in the oral flora due to microbial contamination & 15.9 & 30.4 & 53.7 \\
\hline & Resorption of the alveolar bone as a result of tissue irritation & 33.3 & 43.5 & 23.2 \\
\hline \multirow[t]{6}{*}{9} & DAs can be useful in the following clinical situations & & & \\
\hline & To help stabilize trial base denture during jaw relation visit & 23.2 & 14.5 & 62.3 \\
\hline & To reduce the patients' fears while trying the trial dentures & 21.8 & 21.7 & 56.5 \\
\hline & $\begin{array}{l}\text { To enhance retention, comfort, and function during the } \\
\text { interim period after insertion of immediate dentures }\end{array}$ & 8.7 & 15.9 & 75.4 \\
\hline & $\begin{array}{l}\text { To overcome patients' anxiety after the insertion of } \\
\text { new complete dentures in the first } 2-3 \text { weeks }\end{array}$ & 13.1 & 18.8 & 68.1 \\
\hline & $\begin{array}{l}\text { To provide additional retention and stability for } \\
\text { patients who have inadequate oral anatomy }\end{array}$ & 11.6 & 13 & 75.4 \\
\hline 10 & $\begin{array}{l}\text { Patient education on the use and/or misuse of DAs } \\
\text { is important for patients with ill-fitting dentures }\end{array}$ & 27.6 & 11.6 & 60.8 \\
\hline 11 & $\begin{array}{l}\text { Patient education on the use and/or misuse of DAs } \\
\text { is important for patients with well-fitting dentures }\end{array}$ & 5.8 & 13 & 81.2 \\
\hline 12 & $\begin{array}{l}\text { Overall, DAs can be a beneficial adjunct to } \\
\text { the dentists when fabricating dentures }\end{array}$ & 8.7 & 20.3 & 71 \\
\hline 13 & $\begin{array}{l}\text { Recognizing that some patients may independently choose } \\
\text { to use a DA, dentists should routinely inform patients of the } \\
\text { proper use and misuse of DAs }\end{array}$ & 4.3 & 8.7 & 87 \\
\hline
\end{tabular}


anxiety after insertion of new denture, and to provide additional retention and stability for patients who have inadequate oral anatomy.

There was an overall agreement that DAs aid in patient education with ill- and well-fitting dentures. In addition, there was an agreement that DAs can be beneficial adjunct to the dentists when fabricating dentures, and dentists should routinely inform patients of the proper use and misuse of DAs.

\section{DISCUSSION}

Denture retention is a major factor in the quality of life for wearers of removable prostheses. ${ }^{[17]}$ DAs have been considered a useful adjunct to enhance denture retention, stability, and comfort. ${ }^{[12]}$

The purpose of this study was to assess the knowledge and attitudes of dental interns regarding DAs. Dental interns' knowledge is an indication of undergraduate education about DAs. A high percentage of interns knew about, had used, and had prescribed DAs at some point during their practice and study as undergraduate dental students. This shows that education about DAs is an integral part of the undergraduate prosthodontic curriculum at KSUCD. This is also indicated by the fact that interns rated lectures as their primary source of information about DAs.

About two-thirds of the interns had seen DAs in clinical practice, this can be explained because most of the dental professionals show DAs to their students in the clinic as a part of demonstration even if the student will not use it. However, only approximately, half of them had used DAs or recommended their patients to use them. These findings should be considered when conducting further research on the reasons for not using DAs, particularly at the fitting stage of trial dentures.

The majority of the respondents were in strong agreement regarding the benefits of DAs, which include enhancing the fit of the prosthesis $(87.1 \%)$ and providing psychological comfort to the patients (84.1\%). In the current survey, fewer respondents agreed about the negative aspects of DA use, including that DAs promoted avoidance of good clinical practice (40.6\%). Furthermore, the respondents who thought that DAs mask the underlying denture problems and prevent patients from seeing the dentist for recall visits were $37.7 \%$ and $33.4 \%$, respectively. The results pointed out the awareness of the respondents of proper fabrication steps, since they noticed that DAs would not prevent patients from recognizing that the denture was not fitting properly.

Respondents agreed that DAs contribute to the development of denture stomatitis (52.2\%), candidiasis $(66.7 \%)$, and imbalance in the oral flora $(53.7 \%)$, but not to the development of oral cancer $(2.8 \%)$ or leukoplakia $(8.7 \%)$. On the other hand, the participants were indifferent, as DAs lead to resorption of the alveolar bone $(43.5 \%)$. However, some of the aforementioned viewpoints contradict the available scientific evidence on the biocompatibility of DAs, which does not support the adverse effects of the long-term use of adhesives. ${ }^{[18-20]}$

Participants agreed that DAs are useful for stabilizing trial bases during the early stages of denture fabrication $(62.3 \%)$, enhancing retention during the interim period after insertion (75.4\%), and providing additional retention for patients with inadequate oral anatomy $(75.4 \%)$. In addition, there was an agreement that DAs help patients overcome anxiety after the insertion of new complete dentures $(68.1 \%)$. There was a statistically significant difference between male and female interns whether DAs enhance retention after the insertion of immediate denture; this finding mostly related to their clinical finding during treatment.

Participants had comparatively stronger opinions regarding whether patient education on the use of DAs is an important part of denture service for patients with well-fitting dentures $(81.2 \%)$ and ill-fitting dentures $(60.8 \%)$. This might be explained by the fact that dental interns thought that educating patients with ill-fitting denture on the use of DAs would encourage patients to stop using DAs due to a lack of improvement.

In addition, participants strongly agreed that DAs can be a beneficial adjunct in the fabrication of dentures $(71 \%)$ and that dentists should routinely inform all denture patients of the proper use and misuse of DAs $(87 \%)$. This result showed the moral attitude of dental interns toward DAs.

\section{CONCLUSION}

The results indicate that dental educational program in KSUCD was adequate since most of the participants have adequate knowledge and attitude toward DAs.

Limitations of the current study could be related to the sample selection. Further research should compare the perceptions of dental students/interns to those 
of dental educators. In addition, comparing patients' perspectives on DAs to those of clinicians is useful in determining the gap in patient education regarding their use.

\section{Acknowledgments}

This research project was supported by a grant from the "Research Center of the Female Scientific and Medical Colleges," Deanship of Scientific Research, King Saud University.

\section{Financial support and sponsorship Nil.}

\section{Conflicts of interest}

There are no conflicts of interest.

\section{REFERENCES}

1. Coates AJ. Usage of denture adhesives. J Dent 2000;28:137-40.

2. Grasso JE. Denture adhesives: Changing attitudes. J Am Dent Assoc 1996;127:90-6.

3. Kumar PR, Shajahan PA, Mathew J, Koruthu A, Aravind P, Ahammed MF. Denture adhesives in prosthodontics: An overview. J Int Oral Health 2015;7 Suppl 1:93-5.

4. Duqum I, Powers KA, Cooper L, Felton D. Denture adhesive use in complete dentures: Clinical recommendations and review of the literature. Gen Dent 2012;60:467-77.

5. Slaughter A, Katz RV, Grasso JE. Professional attitudes toward denture adhesives: A Delphi technique survey of academic prosthodontists. J Prosthet Dent 1999;82:80-9.

6. Mckevitt FH. The measured vertical dimension and denture adhesive powders. J Prosthet Dent 1951;1:393-401.
7. Adisman IK. The use of denture adhesives as an aid to denture treatment. J Prosthet Dent 1989;62:711-5.

8. Shay K. Denture adhesives. Choosing the right powders and pastes. J Am Dent Assoc 1991;122:70-6.

9. Divaris K, Ntounis A, Marinis A, Polyzois GL, Polychronopoulou A. Patients' profiles and perceptions of complete dentures in a university dental clinic. Int J Prosthodont 2012;25:145-7.

10. Kelsey CC, Lang BR, Wang RF. Examining patients' responses about the effectiveness of five denture adhesive pastes. J Am Dent Assoc 1997; 128:1532-8.

11. Ozcan M, Kulak Y, Arikan A, Silahtar E. The attitude of complete denture wearers towards denture adhesives in Istanbul. J Oral Rehabil 2004;31:131-4.

12. Polyzois GL, de Baat C. Attitudes and usage of denture adhesives by complete denture wearers: A survey in Greece and the Netherlands. Gerodontology 2012;29:e807-14.

13. Fakhri H, Fayaz A, Faramarzi F, Javaheri HH. The knowledge and attitude of general dentists toward denture adhesives in Tehran. Indian J Dent Res 2009;20:164-8.

14. Shah RJ, Lagdive SB, Talkal AK, Agrawal H, Darji B. Knowledge and attitude towards denture adhesives: A survey on dentists and complete denture wearers. Int J Prosthodont Restor Dent 2015;5:74-80.

15. Hong G, Lian YM, Sadamori S, Hamada T, Murata H. A questionnaire survey of dentists and dental students in China about denture adhesives. Int Chin J Dent 2008;8:33-7.

16. Sadamori S, Hamada T, Hong G, Kawamura M, Nakai N, Razak A. Is it possible to distinguish the understanding of denture adhesive between Japanese dental students and Indonesian peers by a questionnaire? Dent J 2006;39:89-91.

17. Al-Imam H, Özhayat EB, Benetti AR, Pedersen AM, Gotfredsen K. Oral health-related quality of life and complications after treatment with partial removable dental prosthesis. J Oral Rehabil 2016;43:23-30.

18. Tarbet WJ, Grossman E. Observations of denture-supporting tissue during six months of denture adhesive wearing. J Am Dent Assoc 1980;101:789-91.

19. Kim E, Driscoll CF, Minah GE. The effect of a denture adhesive on the colonization of Candida species in vivo. J Prosthodont 2003;12:187-91.

20. Ozkan YK, Uçankale M, Ozcan M, Uner N. Effect of denture adhesive on the micro-organisms in vivo. Gerodontology 2012;29:9-16. 